\title{
Glycemic Thresholds for Activation of Glucose Counterregulatory Systems Are Higher than the Threshold for Symptoms
}

\author{
Natalie S. Schwartz, William E. Clutter, Suresh D. Shah, and Philip E. Cryer \\ Metabolism Division of the Department of Medicine, and the General Clinical Research Center and Diabetes \\ Research and Training Center, Washington University School of Medicine, St. Louis, Missouri 63110
}

\begin{abstract}
To define glycemic thresholds for activation of glucose counterregulatory systems and for symptoms of hypoglycemia, we measured these during stepped reductions in the plasma glucose concentration (in six 10-mg/dl hourly steps) from 90 to $40 \mathrm{mg} / \mathrm{dl}$ under hyperinsulinemic clamp conditions, and compared these with the same measurements during euglycemia $(90 \mathrm{mg} / \mathrm{dl})$ under the same conditions over $6 \mathrm{~h}$ in 10 normal humans. Arterialized venous plasma glucose concentrations were used to calculate glycemic thresholds of $69 \pm 2 \mathrm{mg} / \mathrm{dl}$ for epinephrine secretion, $68 \pm 2 \mathrm{mg} / \mathrm{dl}$ for glucagon secretion, $66 \pm 2 \mathrm{mg} / \mathrm{dl}$ for growth hormone secretion, and $58 \pm 3 \mathrm{mg} / \mathrm{dl}$ for cortisol secretion. In contrast, the glycemic threshold for symptoms was $53 \pm 2 \mathrm{mg} / \mathrm{dl}$, significantly lower than the thresholds for epinephrine $(P$ $<0.001)$, glucagon $(P<0.001)$, and growth hormone $(P<0.01)$ secretion. Thus, the glycemic thresholds for activation of glucose counterregulatory systems during decrements in plasma glucose lie within or just below the physiologic plasma glucose concentration range, and are substantially higher than the threshold for hypoglycemic symptoms in normal humans. These findings provide further support for the concept that glucose counterregulatory systems are involved in the prevention, as well as the correction, of hypoglycemia.
\end{abstract}

\section{Introduction}

A body of physiological and clinical evidence (reviewed in references 1 and 2) indicates that the prevention (3-6), as well as the correction (7-9), of hypoglycemia is the result of both dissipation of insulin and activation of glucose counterregulatory systems. Whereas insulin is the dominant glucose-lowering factor, there are redundant glucose counterregulatory factors, and a hierarchy among these. In defense against decrements in plasma glucose, dissipation of insulin is likely most important. Glucagon plays a primary counterregulatory role. Epinephrine is not normally critical but it compensates largely and becomes critical when glucagon is deficient. Hypoglycemia develops or progresses when both glucagon and epinephrine are deficient and insulin is present. Growth hormone (10), cortisol (10), and glucose autoregulation $(11,12)$ may be involved in the correction of hypoglycemia under some conditions, but these are neither critical

Address correspondence to Dr. Cryer, Metabolism Div., Box 8127, Washington U. School of Medicine, 660 S. Euclid Ave., St. Louis, MO 63110 .

Received for publication 8 August 1986.

J. Clin. Invest.

(C) The American Society for Clinical Investigation, Inc.

0021-9738/87/03/0777/05 \$1.00

Volume 79, March 1987, 777-781 nor potent. Other hormones, neurotransmitters, and effects of substrates other than glucose have not been shown to be involved.

If glucose counterregulatory systems are involved in the prevention of hypoglycemia, these should be activated by plasma glucose decrements within or just below the physiologic range of plasma glucose concentrations, and at glucose levels higher than those that produce symptoms of hypoglycemia. Thus, we hypothesized that during decrements in plasma glucose the glycemic thresholds for activation of glucose counterregulatory systems are higher than the glycemic threshold for symptoms.

To test this hypothesis we measured counterregulatory factors and symptoms during controlled plasma glucose decrements under hyperinsulinemic clamp conditions, and compared these with the same measurements during euglycemia under the same conditions in normal humans. Reasoning that stepped plasma glucose decrements would define glycemic thresholds more precisely than a continuous decrease in plasma glucose, we lowered the plasma glucose concentration in $10-\mathrm{mg} / \mathrm{dl}$ hourly steps.

\section{Methods}

Subjects. 10 normal young adults (nine men and one woman) gave their written consent to participate in these studies, which were approved by the Washington University Human Studies Committee and done at the Washington University General Clinical Research Center. Their ages ranged from 23 to $34 \mathrm{yr}$ (mean $\pm \mathrm{SD}, 26 \pm 3 \mathrm{yr}$ ). Their percent ideal body weights (Metropolitan Life Insurance Co. [New York, NY] tables) ranged from 92 to $113 \%(100 \pm 7 \%)$. Each subject participated in two studies, an experimental and a control study, both after an overnight fast.

Protocol. After reporting to the Washington University General Clinical Research Center early on the morning of study, the subject assumed the recumbent position which was maintained throughout. Three indwelling intravenous lines were then inserted: an antecubital line for Biostator (Miles Laboratories, Inc., Elkhart, IN) sampling, an antecubital line for Biostator glucose infusion and Harvard pump (Harvard Equipment Co., Natick, MA) insulin infusion, and a hand vein line for sampling. That hand was placed in a $60^{\circ}-65^{\circ} \mathrm{C}$ box to provide arterialized venous samples.

On one occasion (the experimental study), purified porcine regular insulin (Novo Industri, Bagsvaerd, Denmark) was infused intravenously at a constant rate (see below) over $6 \mathrm{~h}$ and the plasma glucose concentration was clamped by variable intravenous glucose infusion using the Biostator operating in mode 9:1, at sequential target glucose concentrations of $90,80,70,60,50$, and $40 \mathrm{mg} / \mathrm{dl}$ at $1-\mathrm{h}$ intervals. On another occasion (the control study) insulin was infused at the same rate but plasma glucose was clamped at a target glucose concentration of $90 \mathrm{mg}$ / $\mathrm{dl}$ over $6 \mathrm{~h}$. The subject was not informed whether the plasma glucose concentration was being decreased (experimental study) or held constant (control study).

Arterialized venous blood samples were drawn at 10 -min intervals from 0 through $360 \mathrm{~min}$ during both studies. These were distributed to the appropriate tubes, kept on ice, and centrifuged promptly. The supernatants were then frozen for subsequent analysis. Blood pressures and heart rates were recorded automatically (Dinamap Vital Signs Monitor, model 1846; Critikon Inc., Tampa, FL) after each sample. Also at 
10-min intervals the subject scored, from 0 (none) to 10 (severe), each of the following symptoms: difficulty thinking, shaky, tired, hungry, sweating, heart pounding, nervous, dizzy, faint, tingling, blurred vision, and different in any way. The sum of these 12 numbers constituted the symptom score. The symptom check list was self administered.

In the first three subjects, an intravenous insulin infusion dose of 1.0 $\mathrm{mU} \cdot \mathrm{kg}^{-1} \cdot \mathrm{min}^{-1}$ was used in both the experimental and control studies. However, it was necessary to increase the insulin infusion rate during the 6th hour of the experimental study to achieve the final glucose step, from 50 to $40 \mathrm{mg} / \mathrm{dl}$. Therefore, an insulin infusion dose of 2.0 $\mathrm{mU} \cdot \mathrm{kg}^{-1} \cdot \mathrm{min}^{-1}$ was used in both the experimental and control studies in the remaining seven subjects.

Analytical methods. Plasma glucose was measured with a glucose oxidase method using a glucose analyzer (Beckman Instruments, Inc., Fullerton, CA). Plasma insulin (13), C-peptide (14), glucagon (15), growth hormone (16), and cortisol (17) were measured with radioimmunoassays, plasma norepinephrine and epinephrine with a single isotope derivative (radioenzymatic) method (18). Serum free fatty acids were measured with a colorimetric method (19), blood lactate (20), alanine (21), and $\beta$ hydroxybutyrate (22) with microfluorimetric methods. The performance characteristics of these assays have been described previously (23).

Statistical methods. Glycemic thresholds for various parameters were determined by two methods: (a) estimated by inspection of mean experimental and control data; and $(b)$ calculated as the mean of the glucose concentrations for each individual, during the experimental study, at which a given parameter first exceeded the $95 \%$ confidence interval (determined from the euglycemic control group data) for that parameter at the corresponding time point, after adjustment of experimental and control baseline (1st hour) data to zero. Calculated glycemic thresholds for the various parameters and hourly glucose infusion rates were compared using a $t$ test. In this manuscript data are expressed as the mean plus or minus the standard error, except where the standard deviation is specified.

\section{Results}

Glucose, insulin, and C-peptide (Fig. 1). Mean ( \pm SD) postabsorptive arterialized venous plasma glucose concentrations, before insulin infusions, were $91 \pm 7 \mathrm{mg} / \mathrm{dl}$. The observed range was from 75 to $106 \mathrm{mg} / \mathrm{dl}$.

During the experimental study target plasma glucose levels were approximated reasonably well. Mean $( \pm S E)$ plasma glucose concentrations at the end of each hourly step (with the target levels in parentheses) were: $89 \pm 2(90), 80 \pm 1$ (80), $70 \pm 1$ (70), $62 \pm 1(60), 48 \pm 1(50)$, and $43 \pm 2(40) \mathrm{mg} / \mathrm{dl}$. The corresponding

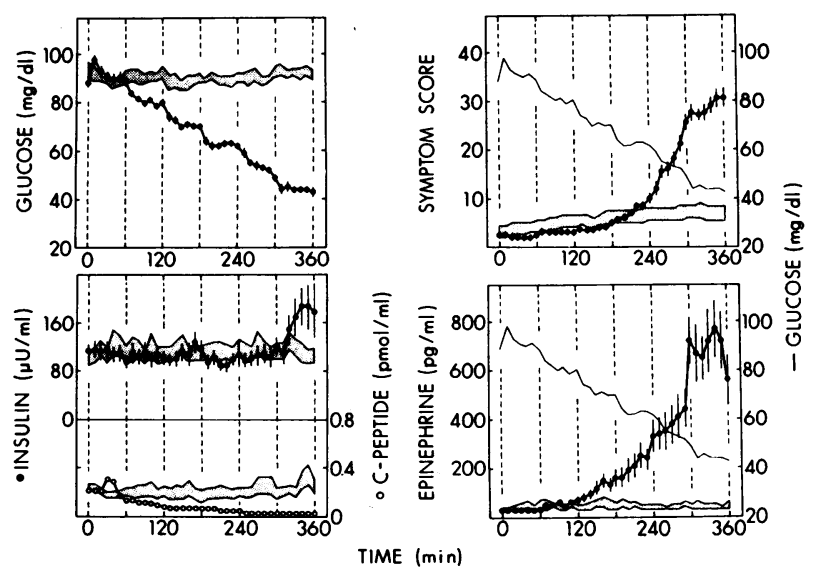

Figure 1. Mean ( $\pm \mathrm{SE})$ plasma glucose, insulin, C-peptide, and epinephrine concentrations and mean symptom score during stepped plasma glucose reductions $(\bullet, 0)$ and during euglycemia ( $(\mathbf{\Xi})$. plasma glucose values during the control study, in which the target was $90 \mathrm{mg} / \mathrm{dl}$, were: $91 \pm 3,93 \pm 3,90 \pm 2,90 \pm 2,92 \pm 2$, and $92 \pm 2 \mathrm{mg} / \mathrm{dl}$. During the experimental study mean glucose concentrations were reasonably stable over the final $30 \mathrm{~min}$ of each step, except that targetted at $50 \mathrm{mg} / \mathrm{dl}$ where the mean level drifted downward.

Stable hyperinsulinemia was comparable throughout the experimental and control studies except during the last hour of the former, when insulin infusion rates were increased in three subjects as noted earlier. Plasma C-peptide concentrations were stable throughout the euglycemic control study but suppressed markedly as the plasma glucose concentration decreased in the experimental study.

Glucose infusion rates (Table I). The average hourly glucose infusion rates required to maintain euglycemia during hyperinsulinemia increased progressively over the $6 \mathrm{~h}$ of the control study. In the experimental study, the first three glucose step levels (to final plasma glucose concentrations of $89 \pm 2,80 \pm 1$, and $70 \pm 1$ $\mathrm{mg} / \mathrm{dl}$ ) during hyperinsulinemia were achieved without absolute reductions in the glucose infusion rates. Substantial reductions in the glucose infusion rates were required to achieve the subsequent three glucose steps.

Symptom score (Fig. 1). The mean symptom score began to increase during the $70-60-\mathrm{mg} / \mathrm{dl}$ plasma glucose step and clearly exceeded control values during the $60-50-\mathrm{mg} / \mathrm{dl}$ glucose step in the experimental study. It rose progressively as plasma glucose decreased thereafter. Notably, the mean symptom score tended to drift upward over time in the euglycemic control study.

Epinephrine (Fig. 1) and glucagon, growth hormone, cortisol, and norepinephrine (Fig. 2). The mean plasma epinephrine concentration doubled (from $34 \pm 7$ to $68 \pm 17 \mathrm{mg} / \mathrm{ml}$ ) during the $90-80-\mathrm{mg} / \mathrm{dl}$ glucose step and clearly exceeded euglycemic control values during the $80-70-\mathrm{mg} / \mathrm{dl}$ glucose step in the experimental study. Epinephrine levels rose substantially as plasma glucose decreased thereafter. The mean plasma glucagon concentration increased and exceeded euglycemic control values during the $70-60-\mathrm{mg} / \mathrm{dl}$ glucose step and rose thereafter in the experimental study. There was, however, considerable variation in glucagon levels, which tended to decline during the control study. The mean plasma growth hormone concentration rose sharply and exceeded control values during the $80-70-\mathrm{mg} / \mathrm{dl}$ glucose step, and increased substantially as plasma glucose de-

Table I. Glucose Infusion Rates during Euglycemic Hyperinsulinemia (Control) and during Stepped Decrements in Plasma Glucose (Experimental) in Normal Humans

\begin{tabular}{|c|c|c|c|c|}
\hline \multirow[b]{2}{*}{ Time } & \multicolumn{2}{|l|}{ Control } & \multicolumn{2}{|l|}{ Experimental } \\
\hline & $\begin{array}{l}\text { Final glucose } \\
\text { concentration }\end{array}$ & $\begin{array}{l}\text { Glucose } \\
\text { infusion rate }\end{array}$ & $\begin{array}{l}\text { Final glucose } \\
\text { concentration }\end{array}$ & $\begin{array}{l}\text { Glucose } \\
\text { infusion rate }\end{array}$ \\
\hline $\min$ & $m g / d l$ & $\mathrm{mg} \cdot \mathrm{kg}^{-1} \cdot \mathrm{min}^{-1}$ & $m g / d l$ & $m g \cdot \mathrm{kg}^{-1} \cdot \mathrm{min}^{-1}$ \\
\hline $0-60$ & $91 \pm 3$ & $6.0 \pm 0.9$ & $89 \pm 2$ & $6.3 \pm 0.8$ \\
\hline $60-120$ & $93 \pm 3$ & $7.9 \pm 0.8$ & $80 \pm 1$ & $6.5 \pm 0.6$ \\
\hline $120-180$ & $90 \pm 2$ & $8.6 \pm 0.9$ & $70 \pm 1$ & $6.6 \pm 0.7$ \\
\hline $180-240$ & $90 \pm 2$ & $9.2 \pm 0.8$ & $62 \pm 2$ & $5.6 \pm 0.9^{*}$ \\
\hline $240-300$ & $92 \pm 2$ & $9.6 \pm 0.7$ & $48 \pm 1$ & $3.3 \pm 0.9^{\ddagger}$ \\
\hline $300-360$ & $92 \pm 2$ & $10.1 \pm 1.0$ & $43 \pm 2$ & $1.2 \pm 0.5^{\ddagger}$ \\
\hline
\end{tabular}

\footnotetext{
$* P<0.01$ versus control.
}

${ }^{\ddagger} P<0.001$ versus control. 


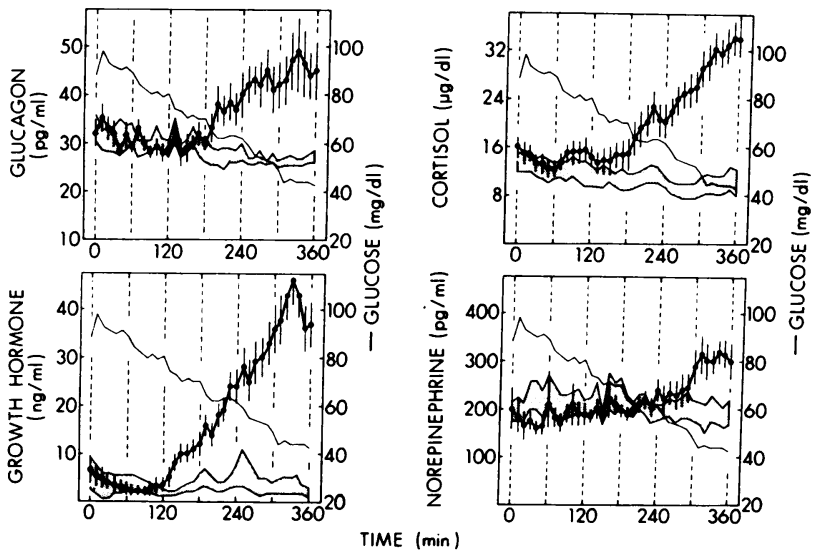

Figure 2. Mean ( $\pm \mathrm{SE}$ ) plasma glucagon, growth hormone, cortisol, and norepinephrine concentrations during stepped plasma glucose reductions (๑) and during euglycemia ( $\bullet$ ).

creased thereafter in the experimental study. Some variation in growth hormone levels was apparent in the control study, as observed previously under other conditions (3). The mean plasma cortisol concentration clearly increased and exceeded control values during the $70-60-\mathrm{mg} / \mathrm{dl}$ glucose step, and rose progressively as plasma glucose decreased thereafter in the experimental study. Although it drifted upward earlier, the mean plasma norepinephrine concentration did not exceed control values until the $50-40-\mathrm{mg} / \mathrm{dl}$ glucose step in the experimental study.

Free fatty acids, $\beta$-hydroxybutyrate, lactate, and alanine (Fig. 3 ). In the experimental study the mean serum free fatty acid concentration increased, clearly exceeding control values during the $70-60-\mathrm{mg} / \mathrm{dl}$ glucose step. The mean blood $\beta$-hydroxybutyrate concentration appeared to exceed control values only during the last glucose step. The mean blood lactate concentration increased and exceeded control values during the 70-60$\mathrm{mg} / \mathrm{dl}$ glucose step, and rose progressively as plasma glucose decreased thereafter in the experimental study. The mean blood alanine concentration did not change in either study.

Heart rate and blood pressure (data not shown). Mean heart

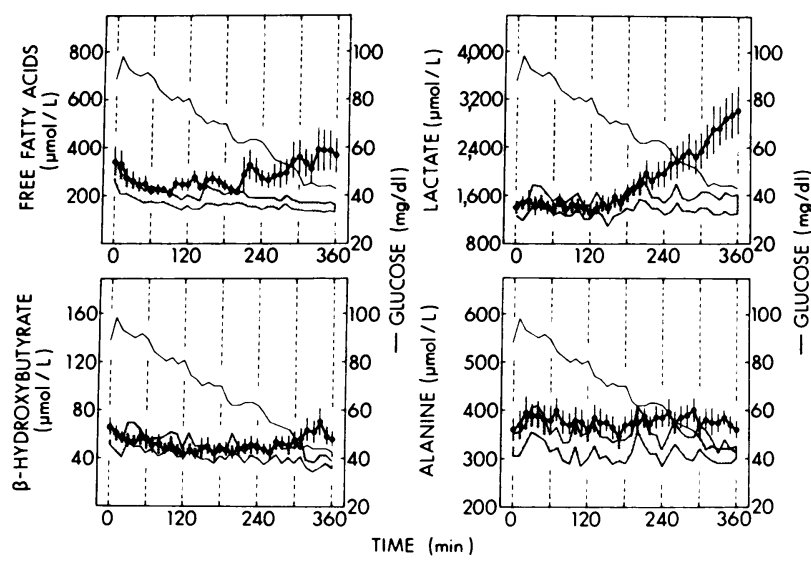

Figure 3. Mean $( \pm \mathrm{SE})$ serum free fatty acid and blood $\beta$-hydroxybutyrate, lactate, and alanine concentrations during stepped plasma glucose reductions ( $\bullet$ ) and during euglycemia ( $(\mathbb{})$. rate and systolic and diastolic blood pressures in the experimental study did not deviate appreciably from those in the control study.

Glycemic thresholds. Arterialized venous glycemic thresholds for symptoms and for activation of glucose counterregulatory systems are shown in Fig. 4. As can be seen, the calculated glycemic threshold for symptoms $(53 \pm 2 \mathrm{mg} / \mathrm{dl})$ was significantly lower than the glycemic thresholds for increments in plasma epinephrine $(69 \pm 2 \mathrm{mg} / \mathrm{dl}, P<0.001)$, glucagon $(68 \pm 2 \mathrm{mg} / \mathrm{dl}$, $P<0.001)$, and growth hormone $(66 \pm 2 \mathrm{mg} / \mathrm{dl}, P<0.01)$. The glycemic threshold for cortisol secretion $(58 \pm 3 \mathrm{mg} / \mathrm{dl})$ tended to exceed that for symptoms, but not significantly so. The glycemic threshold for an increment in plasma norepinephrine $(51 \pm 3 \mathrm{mg} / \mathrm{dl})$ was similar to that for symptoms.

\section{Discussion}

These data indicate that the glycemic thresholds for activation of glycose counterregulatory systems (including the secretion of epinephrine, glucagon, and growth hormone) during decrements in plasma glucose lie within, or just below, the physiologic plasma glucose concentration range in normal humans. Normal arterialized venous plasma glucose concentrations have not been well defined under a variety of conditions. If one assumes that the observed (75-106 mg/dl) or statistical (mean $\pm 2 \mathrm{SD}, 77-105 \mathrm{mg}$ / dl) range of postabsorptive values in these subjects represents the physiologic range, the calculated glycemic thresholds for epinephrine $(69 \pm 2 \mathrm{mg} / \mathrm{dl})$, glucagon $(68 \pm 2)$, and growth hormone $(66 \pm 2 \mathrm{mg} / \mathrm{dl})$ secretion lie just below the physiologic range. $T$ The data also indicate that the glycemic thresholds for activation of glucose counterregulatory systems are substantially higher than the threshold for hypoglycemic symptoms $(53 \pm 2 \mathrm{mg} / \mathrm{dl})$. These findings provide further support for the concept, based upon physiological and clinical evidence (1-6), that glucose counterregulatory systems are involved in the prevention, as well as the correction, of hypoglycemia in humans.

These glycemic thresholds for symptoms and for activation of glucose counterregulatory systems during decrements in plasma glucose should not be extrapolated to other conditions uncritically. First, the glycemic thresholds were determined in a small, reasonably homogenous group of normal young adults. Second, they represent estimates, albeit possibly underestimates, of the biologic thresholds. Since the glycemic thresholds were based upon the plasma glucose concentration at which experimental values first exceeded the $95 \%$ confidence interval for that parameter during the euglycemic control study, these represent

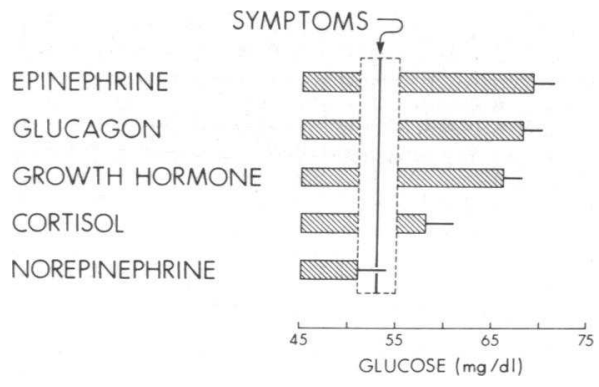

Figure 4. Mean ( \pm SE) arterialized venous glycemic thresholds for symptoms and for activation of glucose counterregulatory systems (including increments in plasma epinephrine, glucagon, growth hormone, cortisol, and norepinephrine) during decrements in plasma glucose. 
conservative threshold values that might be lower than the biologic thresholds. Increments in counterregulatory factor release and in symptoms must have begun earlier, before the values exceeded the $95 \%$ confidence intervals. Since the signal must precede the response by some finite time interval (i.e., the signal and the response cannot be simultaneous), these responses might have been signalled at higher glucose levels despite the use of hourly stepped plasma glucose decrements. Indeed, from inspection of mean data it appears that the average glycemic thresholds for epinephrine and growth hormone release are $>70$ $\mathrm{mg} / \mathrm{dl}$, perhaps $>80 \mathrm{mg} / \mathrm{dl}$. Third, the glycemic thresholds were determined from arterialized venous blood samples. Although arteriovenous differences in plasma glucose are negligible in the postabsorptive state, substantial gradients $(\sim 15-30 \%$ at maximum) develop after glucose ingestion $(24,25)$. To the extent that such glucose extraction is the result of hyperinsulinemia, the venous glucose concentrations under the present hyperinsulinemic conditions were likely lower than the arterialized venous values reported here. The latter can be viewed as estimates of biologic thresholds for counterregulatory activation and symptoms, but they should not be compared with venous glucose levels under other conditions.

The glycemic threshold for increments in plasma cortisol $(58 \pm 3 \mathrm{mg} / \mathrm{dl})$ was lower than those for increments in epinephrine, glucagon, or growth hormone. Rather than reflecting a lower threshold for activation of the hypothalamic-pituitary-adrenocortical axis, this might have been due to delay in the response of cortisol secretion to increments in ACTH, which was not measured. However, the prompt rise in plasma cortisol after injection of corticotropin-releasing hormone $(26,27)$ suggests that there was little delay in detection of ACTH increments, and supports the possibility that the glycemic threshold for release of ACTH is indeed lower than the thresholds for release of other counterregulatory hormones.

The relatively low glycemic threshold for increments in plasma norepinephrine $(51 \pm 3 \mathrm{mg} / \mathrm{dl})$ contrasts with the relatively high threshold for increments in plasma epinephrine $(69 \pm 2 \mathrm{mg} /$ dl). A substantial proportion, if not all, of the plasma norepinephrine response to hypoglycemia is derived from the adrenal medullae (28). However, muscle sympathetic nerve activity increases during hypoglycemia in humans (29); in general, muscle sympathetic nerve activity correlates well with the plasma norepinephrine concentration $(30,31)$. If the increments in plasma norepinephrine in the present study are indicative of sympathetic neural, as well as adrenomedullary, activation, the concordance of the norepinephrine $(51 \pm 3 \mathrm{mg} / \mathrm{dl})$ and symptom $(53 \pm 2 \mathrm{mg} /$ dl) glycemic thresholds is consistent with the notion that some of the nonneuroglycopenic symptoms of hypoglycemia are the result of a sympathetic neural, rather than an adrenomedullary, discharge. Although a symptom such as palpitations might be attributable to circulating catecholamines, sweating, a prominent symptom, is at best partially explicable on this basis $(32,33)$. It is largely attributable to sympathetic postganglionic cholinergic activation (32-34).

Several other observations from the present study warrant comment. First, the late rise in serum free fatty acid concentrations during hypoglycemia suggests that increased sympathochromaffin catecholamine release, perhaps in concert with other factors including increased growth hormone levels, can override the antilipolytic effect of sustained hyperinsulinemia. Second, since plasma C-peptide concentrations were suppressed completely during decrements in plasma glucose, but not during euglycemic hyperinsulinemia of similar magnitude, the data indicate that decrements in plasma glucose during hyperinsulinemia are more potent than hyperinsulinemia per se in suppressing insulin secretion. Third, since the glucose infusion rates required to maintain euglycemia increased progressively in the control study, steady state was not achieved. This has been reported by others during similar hyperinsulinemic clamps (35). If endogenous glucose production was suppressed completely, a reasonable assumption at this level of hyperinsulinemia (36), then steady state glucose utilization was also not achieved. Notably, absolute reductions in glucose infusion rates were not required to achieve the first three glucose step levels (to $70 \pm 1 \mathrm{mg}$ / dl) in the experimental study although substantial reductions were required to achieve lower glucose levels. Our experimental design does not permit distinction between the roles of reduced plasma glucose concentrations per se and of resistance to insulin action induced by activated counterregulatory systems in this reduced glucose utilization. Fourth, despite substantial increments in plasma epinephrine we observed no significant changes in heart rate or blood pressure. The most plausible explanation is that the hemodynamic effects were counteracted by an increase in parasympathetic activity. Thus, during gradual decrements in plasma glucose, hemodynamic changes may not reflect the extent of sympathochromaffin activation.

Lastly, the data document the technical feasibility of the use of stepped plasma glucose decrements in the study of humans, and of the quantitation of symptoms of hypoglycemia using a symptom score. With respect to the latter, the upward drift of the symptom scores during the euglycemic control study underscores the importance of the paired control for studies of responses to plasma glucose decrements.

In summary, the glycemic thresholds for activation of glucose counterregulatory systems during decrements in plasma glucose lie within, or just below, the physiologic plasma glucose concentration range, and are substantially higher than the glycemic threshold for hypoglycemic symptoms in normal humans. These findings provide further support for the concept that glucose counterregulatory systems are involved in the prevention, as well as the correction, of hypoglycemia.

\section{Acknowledgments}

The authors acknowledge the technical assistance of Mr. Krishan Jethi, Ms. Susan Allen, Mr. Bernard Zickmund, Ms. Shirley Hill, Ms. Joy Brothers, Ms. Bakula Trivedi, and Ms. Karen Freeman. The statistical advice of Dr. Curtis Parvin, the data management assistance of Mr. Daniel Weidman, the secretarial support of Ms. Theresa Lautner, and the assistance of the nursing staff, particularly Ms. Virginia Bischof, of the Washington University General Clinical Research Center, are also gratefully acknowledged.

This work was supported in part by U. S. Public Health Service grants AM27085, AM20579, and RR00036.

\section{References}

1. Cryer, P. E., and J. E. Gerich. 1985. Glucose counterregulation, hypoglycemia and intensive insulin therapy of diabetes mellitus. N. Engl. J. Med. 313:232-241.

2. Cryer, P. E., N. H. White, and J. V. Santiago. 1986. The relevance of glucose counterregulatory systems to patients with insulin dependent diabetes mellitus. Endocrine Reviews. 7:131-139.

3. Tse, T. F., W. E. Clutter, S. D. Shah, J. P. Miller, and P. E. Cryer. 1983. Neuroendocrine responses to glucose ingestion in man: specificity, 
temporal relationships and quantitative aspects. J. Clin. Invest. 72:270 277.

4. Tse, T. F., W. E. Clutter, S. D. Shah, and P. E. Cryer. 1983. The mechanisms of postprandial glucose counterregulation in man. J. Clin. Invest. 72:278-286.

5. Rosen, S. G., W. E. Clutter, M. A. Berk, S. D. Shah, and P. E. Cryer. 1984. Epinephrine supports the postabsorptive plasma glucose concentration, and prevents hypoglycemia, when glucagon secretion is deficient in man. J. Clin. Invest. 73:405-411.

6. White, N. H., D. A. Skor, P. E. Cryer, D. M. Bier, L. Levandoski, and J. V. Santiago. 1983. Identification of type 1 diabetic patients at increased risk for hypoglycemia during intensive therapy. $N$. Engl. $J$. Med. 308:485-491.

7. Clarke, W. L., J. V. Santiago, L. Thomas, M. W. Haymond, E. Ben-Galim, and P. E. Cryer. 1979. Adrenergic mechanisms of recovery from hypoglycemia in man: adrenergic blockade. Am. J. Physiol. 236: E147-E152.

8. Gerich, J., J. Davis, M. Lorenzi, R. Rizza, N. Bohannon, J. Karam, S. Lewis, S. Kaplan, T. Schultz, and P. E. Cryer. 1979. Hormonal mechanisms of recovery from insulin-induced hypoglycemia in man. Am. J. Physiol. 236:E380-E385.

9. Rizza, R. A., P. E. Cryer, and J. E. Gerich. 1979. Role of glucagon, epinephrine and growth hormone in human glucose counterregulation. J. Clin. Invest. 64:62-71.

10. DeFeo, P., G. B. Bolli, M. M. Ventura, G. Perriello, S. DeCosmo, C. Lolli, J. E. Gerich, and P. Brunetti. 1985. Studies of the individual counterregulation role of glucagon, catecholamines, growth hormone and cortisol on augmented glucose production and reduced glucose utilization during continuous physiologic hyperinsulinemia in man. Diabetes Res. Clin. Pract. 1(Suppl. 1):S128. (Abstr.)

11. Bolli, G., P. DeFeo, G. Perriello, S. DeCosmo, M. Ventura, P. Campbell, P. Brunetti, and J. Gerich. 1985. Role of hepatic autoregulation in defense against hypoglycemia in humans. J. Clin. Invest. 75:16231637.

12. Hansen, I., R. Firth, M. Haymond, P. Cryer, and R. Rizza. 1986. The role of autoregulation of hepatic glucose production in man: response to a physiologic decrement in plasma glucose. Diabetes. 35:186-191.

13. Hales, C., and P. Randle. 1963. Immunoassay of insulin with insulin antibody precipitate. Biochem. J. 88:137-146.

14. Kuzuya, H., P. M. Blix, D. L. Horwitz, D. F. Steiner, and A. H. Rubenstein. 1977. Determination of free and total insulin and C-peptide in insulin treated diabetics. Diabetes. 26:22-29.

15. Ensinck, J. W. 1983. Immunoassays for glucagon. In Glucagon. Handbook of Experimental Pharmacology, Vol. 66. P. Lefebvre, editor. Springer-Verlag, New York. 203-221.

16. Schalch, D., and M. Parker. 1964. A sensitive double antibody radioimmunoassay for growth hormone in plasma. Nature (Lond.). 203: $1141-1142$.

17. Farmer, R. W., and C. E. Pierce. 1974. Plasma cortisol determination: radioimmunoassay and competitive binding compared. Clin. Chem. 20:411-414.

18. Shah, S. D., W. E. Clutter, and P. E. Cryer. 1985. External and internal standards in the single isotope derivative (radioenzymatic) assay of plasma norepinephrine and epinephrine in normal humans and persons with diabetes or chronic renal failure. J. Lab. Clin. Med. 106:624-629.
19. Novak, M. 1965. Colorimetric ultramicro method for the determination of free fatty acids. J. Lipid Res. 6:431-433.

20. Lowry, O. H., J. V. Passoneau, F. X. Hasselberger, and D. V. Schultz. 1964. Effect of ischemia on known substrates and co-factors of the glycolytic pathway of the brain. J. Biol. Chem. 239:18-30.

21. Cahill, G. F., Jr., M. G. Herrera, A. P. Morgan, J. S. Soeldner, J. Steinke, P. Levy, G. A. Rerchand, Jr., and D. M. Kipnis. 1966. Hormone-fuel interrelationships during fasting. J. Clin. Invest. 45:1751-1769.

22. Pinter, J. D., J. A. Hayaski, and J. A. Watson. 1967. Enzymatic assay of glycerol, dihydroxyacetone and glyceraldehyde. Arch. Biochem. Biophys. 121:404-414.

23. Berk, M. A., W. E. Clutter, D. A. Skor, S. D. Shah, R. P. Gingerich, C. A. Parvin, and P. E. Cryer. 1985. Enhanced glycemic responsiveness to epinephrine in insulin-dependent diabetes mellitus is the result of the inability to secrete insulin. J. Clin. Invest. 75:1842-1851.

24. Jackson, R. A., N. Peters, U. Advani, G. Perry, J. Rogers, W. H. Brough, and T. R. E. Pilkington. 1973. Forearm glucose uptake during the oral glucose tolerance test in normal subjects. Diabetes. 22:442-458.

25. Hampton, S. M., L. M. Morgan, J. A. Tredger, R. Cramb, and V. Marks. 1986. Insulin and C-peptide levels after oral and intravenous glucose. Diabetes. 35:612-616.

26. Orth, D. N., R. V. Jackson, D. S. DeCherney, C. R. Debold, A. N. Alexander, D. P. Island, J. Rivier, C. Rivier, J. Spiess, and W. Vale. 1983. Effect of synthetic ovine corticotropin-releasing factor. $J$. Clin. Invest. 71:587-595.

27. Tsukada, T., Y. Nakai, T. Koh, S. Tsujii, and H. Imura. 1983. Plasma adrenocorticotropin and cortisol responses to intravenous injection of corticotropin-releasing factor in the morning and evening. $J$. Clin. Endocrinol. Metab. 57:869-871.

28. Shah, S. D., T. F. Tse, W. E. Clutter, and P. E. Cryer. 1984. The human sympathochromaffin system. Am. J. Physiol. 247:E380-E384.

29. Fagius, J., F. Niklasson, and C. Berne. 1986. Sympathetic outflow in human muscle nerves increases during hypoglycemia. Diabetes. 35: 1124-1129.

30. Wallin, B. G., G. Sundlof, B.-M. Eriksson, P. Dominiak, H. Grobecker, and L. E. Lindblad. 1981. Plasma noradrenaline correlates to sympathetic muscle nerve activity in normotensive man. Acta Physiol. Scand. 111:69-73.

31. Eckberg, D. L., O. K. Andersson, T. Hedner, R. F. Rea, and B. G. Wallin. 1986. Baroreflex modulation of human sympathetic activity. Clin. Res. 34:628A. (Abstr.)

32. Foster, K. G., J. Ginsburg, and J. S. Weiner. 1970. Role of circulating catecholamines in human eccrine sweat gland control. Clin. Sci. 39:823-832

33. Allen, J. A., and I. C. Broddie. 1972. The role of circulating catecholamines in sweat production in man. J. Physiol. 227:801-814.

34. Corrall, R. J. M., B. M. Frier, N. McD. Davidson, W. M. Hopkins, and E. B. French. 1983. Cholinergic manifestations of the acute autonomic reaction to hypoglycaemia in man. Clin. Sci. 64:49-53.

35. Doberne, L., M. S. Greenfield, B. Schultz, and G. Reaven. 1981. Enhanced glucose utilization during prolonged clamp studies. Diabetes. 30:829-835.

36. Rizza, R. A., L. Mandarino, and J. E. Gerich. 1981. Dose-response characteristics for the effects of insulin on production and utilization of glucose in man. Am. J. Physiol. 240:630-639. 